\title{
Activation of PAR2 or/and TLR4 promotes SW620 cell proliferation and migration via phosphorylation of ERK1/2
}

\author{
BAOCHENG ZHOU ${ }^{1,2}$, HONG ZHOU $^{1}$, SHUCAI LING ${ }^{3}$, DONGLIN GUO ${ }^{1}$, \\ YIHONG YAN $^{1}$, FANG ZHOU ${ }^{1}$ and YING WU $^{1}$
}

\begin{abstract}
${ }^{1}$ Department of Clinical Laboratory and Hematology, Jiangsu University, 301 Xuefu Road, Zhenjiang, Jiangsu 212013; ${ }^{2}$ Department of Clinical Laboratory, Maternal and Child Care Service Centre of Lianyungang, 10 Cangwu Road, Lianyungang, Jiangsu 222006; ${ }^{3}$ Department of Anatomy, Zhejiang University School of Medicine, 388 Yuhangtang Road, Hangzhou, Zhejiang 310031, P.R. China
\end{abstract}

Received August 10,2010; Accepted September 20, 2010

DOI: $10.3892 /$ or.2010.1077

\begin{abstract}
Protease-activated receptor 2 (PAR2) is a G-proteincoupled receptor and its activation has been associated with the pathogenetic progress in certain cancers. Toll-like receptor 4 (TLR4), one member of Toll-like receptors family, is mainly contributed to the innate immune response. However, recent studies have shown that TLR4 is aberrantly expressed in various types of carcinomas and may correlate with tumor progression. Previously, we reported that PAR2 could be expressed in human colon cancer cell line (SW620) and its activation by some stimulants was able to facilitate cell proliferation and migration. In our recent preliminary experiment, it was found that SW620 cells also had TLR4 expression. Thus, we considered that PAR2 and TLR4 could have some collaborative roles in SW620 cells. In the current study, the cross-inducible expression of PAR2 and TLR4 on SW620 cells was investigated, and the functional roles of their activation on the behavior of SW620 cells were evaluated. It was found that activation of PAR2 with PAR2-AP (PAR2 agonist, $100 \mu \mathrm{M}$ ) enhanced TLR4 releasement and vice versa. The activation of PAR2 or TLR4 (with LPS, $100 \mathrm{ng} / \mathrm{ml}$ ) could promote SW620 cell proliferation and migration, and the phosphorylation of ERK1/2 but not p38MAPK, as well as the expression of interleukin 8 (IL-8) and tissue factor (TF). Whereas the caspase-7 expression was decreased under PAR 2 or TLR 4 activation. Furthermore, ERK1/2 inhibitor (U0126, at $10 \mu \mathrm{M}$ ) could intervene in all regulating effects of PAR2 or/and TLR4. Collectively, this study demonstrated that both PAR2 and TLR4 activation on SW620 cells can trigger the phosphorylation of ERK1/2, regulate the expression
\end{abstract}

Correspondence to: Professor Hong Zhou, Department of Clinical Laboratory and Hematology, Jiangsu University, 301 Xuefu Road, Zhenjiang, Jiangsu 212013, P.R. China

E-mail: hongzhou@ujs.edu.cn

Key words: protease-activated receptor 2, Toll-like receptor 4, colonic cancer cells, extracellular regulated protein kinase 1/2 of IL-8, TF and caspase-7, thereby promote the proliferation and migration of cells.

\section{Introduction}

Protease-activated receptors (PARs) are members of a group of seven transmembrane $G$ protein-coupled receptors and are activated by the proteolytic cleavage of their amino terminal domain. To date, four PARs have been discovered and characterized. PAR1, 3, and 4 were the first identified targets for thrombin but can also be activated by trypsin or cathepsin-G (CG). In contrast, PAR2 is resistant to thrombin, but can be activated by trypsin, mast cell tryptase, leukocyte roteinase-3 (PR3), bacteria-derived enzymes, factor Xa, and TF/VIIa complex (1). Experimentally, PARs can also be activated by synthetic peptides (agonist peptides, AP) that mimic the neo-amino terminus of the cleaved receptors. Specific PAR-APs are important tools for investigating the roles of PARs activation (2). It has been widely reported that the activation of PARs by serine proteases contributes to the pathological processes in infection, inflammation, and some cancers (3-5). Specifically, the activation of PAR2 induced by $\mathrm{TF} / \mathrm{VII}$ complex has recently attracted attention due to its involvement in several pathogenetic progresses, such as angiogenesis, cell migration and invasion in certain cancers (6). PAR2 activation can play a part in the reaction mechanism of innate immunity by inducing some molecules secretion, such as pro-inflammatory cytokines and chemokines (7). These functions of PAR2 are similar to the roles of Tolllike receptors (TLRs).

It has been demonstrated that TLRs are type I transmembrane glycoproteins mainly expressed on cells of innate immune system, which is the first-line of host defense against pathogens (8). Lipopolysaccharide (LPS), the main ligand of TLR4, can activate the innate immune system via TLR4, and ultimately lead to targeted gene transcription and induce the release of proinflammatory cytokines, which are contributed to the innate immune response (9). However, the TLR4, normally expressed restrictedly in immune cells, was also found to be aberrantly expressed in various types of carcinomas (10). It was recently demonstrated that TLR4 (at mRNA and protein 
level) was strongly expressed in lung cancer tissues and there was a positive correlation between the expression level of TLR4 and malignancy of lung cancer (11). Furthermore, the activation of TLR4 and its signaling pathway was shown to have a close relationship with the malignant behavior of cancer cells (12).

Mitogen-activated protein kinases (MAPKs) are ubiquitous elements in certain signaling transduction pathways and are involved in many diseases $(13,14)$. MAPKs are mainly consisted of ERK1/2, p38 and JNK/SAPK and can be activated by protein kinases such as MAPK kinase kinases, MAPK kinases. Among MAPKs, ERK1/2 and p38 MAPK are mostly linked to cell proliferation, differentiation and apoptosis in some cancers $(15,16)$. It has been found that ERK1/2 and p38 MAPK were involved in the signaling transduction pathways induced by both PAR2 and TLR4 activation $(17,18)$. On the other hand, the progression of the malignant behavior of cancer can be driven by a great number of factors, including some angiogenic growth factors, chemotactic factors, as well as some antiapoptotic molecules. Of which, interleukin-8 (IL-8) is a key chemokine that has recently been shown to be expressed in many tumor cells and contribute to human cancer progression (19). Tissue factor (TF), besides the roles in coagulation, is believed to have non-clotting functions, including the roles in inflammation, angiogenesis, metastasis, and cell migration (20). Caspase-7, as an executioner caspase, also plays important roles in regulating cells apoptosis (21). Aberrant regulation of the apoptotic pathways, resulting from mutations or excessive activation of the antiapoptotic pathways is intrinsic to the oncogenic process in general and the early stages of metastasis in particular (22).

In our previous study, we observed that PAR2 was highly expressed on colon cancer cell lines (SW620), and PAR2 agonist (SLIGKV-NH2, PAR2-AP) and factor VIIa could enhance SW620 cells proliferation and migration (23). More recently, we found in our preliminary experiment that TLR4 could also be expressed in SW620 cells. Therefore, it was hypothesized by our group that cross-talk or correlation may occur between PAR2 and TLR4 on SW620 cells. In the current study, it was investigated whether the activation of PAR2 could enhance TLR4 secretion, and vice versa. Then the effects of PAR2 or/and TLR4 activation in SW620 cell proliferation and migration were evaluated, and whether some key molecules could be regulated via PAR2 and TLR4 activation was finally investigated.

\section{Materials and methods}

Materials. Leibovitz's L-15 medium and fetal bovine serum (FBS) were obtained from Gibco BRL (Grand Island, NY, USA). PAR2 agonist (SLIGKV-NH2, PAR2-AP) was synthesized by Proteintech Group Inc. (Wuhan, China). LPS and paclitaxel (TLR4 pathway inhibitor) were purchased from Sigma-Aldrich (St. Louis, MO, USA). Monoclonal antiPAR2 antibody was purchased from Zymed Laboratories (South San Francisco, CA, USA). Polyclonal anti-TLR4 and anti-ERK1/2 and anti-p38 MAPK antibodies were from Cell Signaling Technology (Beverly, MA, USA). U0126 (ERK1/2 inhibitor) was obtained from Promega Corp. (Madison, WI,
USA). TRIzol and RT-PCR reagents were purchased from Invitrogen (Carlsbad, CA, USA). All other chemicals and reagents used in experiments were of the best quality commercially available.

Cell lines and cell culture. The human colon cancer cell line SW620 was from Shanghai Institutes for Biological Sciences (Shanghai, China). Cells were cultured in Leibovitz's L-15 medium supplemented with $10 \%$ FBS. Cells were maintained at $37^{\circ} \mathrm{C}$ in a humidified atmosphere of $5 \% \mathrm{CO}_{2}$ and were deprived of serum for $16 \mathrm{~h}$ before they were stimulated with agonists and other reagents.

The assays for PAR2 and TLR4 expression on SW620 cells. The expression of PAR2 and TLR4 on SW620 cells was investigated by quantitative real-time PCR (Q-PCR, for the mRNA levels) and flow cytometry (for their protein levels). Whether the cross-induced expression of PAR2 or TLR4 occurred with TLR4 or PAR2 activation was evaluated. Briefly, the SW620 cells $\left(1 \times 10^{6}\right)$ were stimulated with $100 \mu \mathrm{M}$ of PAR2 agonist (PAR2-AP) or $100 \mathrm{ng} / \mathrm{ml}$ of LPS for different times. The total cell RNAs were prepared for Q-PCR or the cells were analyzed by flow cytometry. The PAR2 forward primer was 5'-TGGCACCATCCAAGGAAC-3' and the reverse primer was 5'-GTCAGCCAAGGCCAGATT-3'. The TLR4 forward primer was 5'-ACCAGAGTTTCCTGCA ATGG-3' and the reverse primer was 5'-AATCTTCTTCC CCACGGAGG-3'. The detailed procedures for Q-PCR is described in 'Quantitative real-time PCR analysis'. The protein expression of PAR2 or TLR4 on cells was measured by flow cytometry (FACS calibur, BD, USA) using the anti-PAR2 or anti-TLR4 antibodies and the FITC-labeled second antibodies (from Santa Cruz Biotechnology, USA). The protein levels of PAR2 or TLR4 on cells are shown as relative luciferase units (RLU).

Cell cycle analysis by flow cytometry. To demonstrate the effects of PAR2 and TLR4 activation on SW620 cell growth and proliferation, flow cytometry analysis was performed to observe the cell cycle distribution. The SW620 cells were seeded into a 6-well plate at a density of $10^{6}$ cells per $\mathrm{ml}$, after maintaining in serum-free medium for $16 \mathrm{~h}$, the cells were treated with PAR2-AP $(100 \mu \mathrm{M})$ or/and LPS $(100 \mathrm{ng} / \mathrm{ml})$ for $8 \mathrm{~h}$. If necessary, the cells were pretreated with anti-PAR2 antibody $(100 \mu \mathrm{M})$ or paclitaxel $(100 \mathrm{ng} / \mathrm{ml})$ for $1 \mathrm{~h}$ or U0126 $(10 \mu \mathrm{M})$ for $15 \mathrm{~min}$ (according to the manufacturer's instructions). The cultured cells were harvested and washed with phosphate-buffered saline (PBS). Then the cells were stained with propidium iodide (PI) at room temperature (RT) for $30 \mathrm{~min}$ in dark. Finally, each sample was analyzed by flow cytometry and the proportion of cells within the $\mathrm{G}_{1}, \mathrm{~S}, \mathrm{G}_{2} / \mathrm{M}$ phases was determined.

Cell migratory assay. Cell migration assays were performed using modified Boyden chambers with a $6.5-\mu \mathrm{m}$ diameter, porous $(8 \mu \mathrm{m})$ polycarbonate membrane separating the two chambers (Transwell, Corning Inc., USA). Cells were harvested by briefly exposure to trpsin/EDTA and neutralized with Leibovitz's L-15 medium. Cells were washed and resuspended in medium with $0.1 \%$ bovine serum albumin 

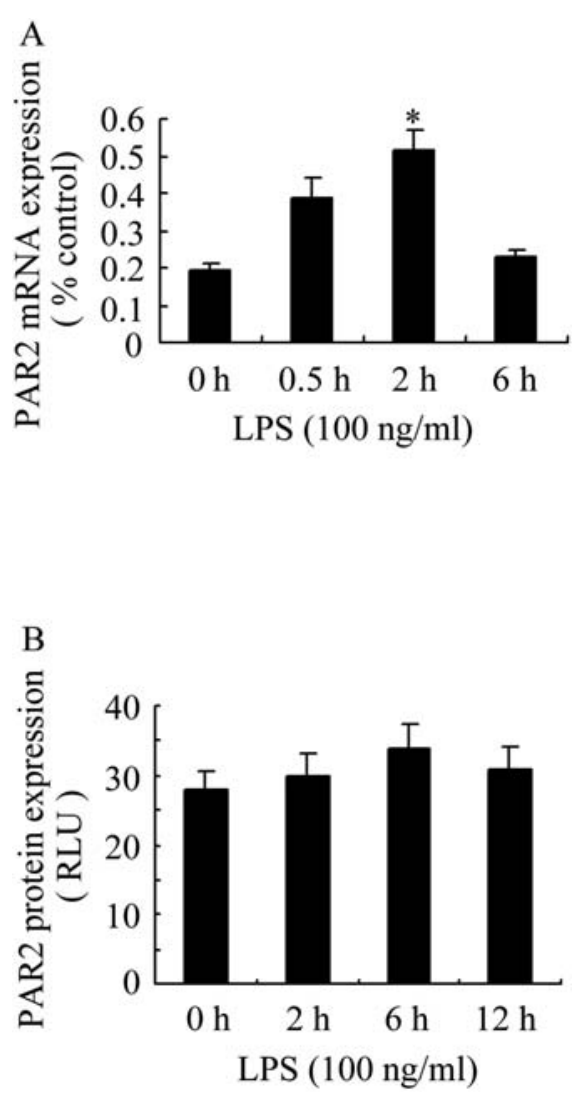

Figure 1. The overexpression of PAR2 caused by LPS. SW620 cells $\left(1 \times 10^{6} / \mathrm{ml}\right)$ were treated with $100 \mathrm{ng} / \mathrm{ml}$ of LPS for different times. The cellular RNA was prepared and the Q-PCR was carried out for the PAR2 mRNA determination as described in Materials and methods. The PAR2 protein level was examined by flow cytometry using anti-PAR2 antibody and FITC-labeled second antibody. (A) The PAR2 mRNA level was normalized to control values of $\beta$-actin (\%). (B) The PAR2 protein level is shown as relative luciferase units (RLU). Data are shown as the mean \pm SEM of triplicate determinations. ${ }^{*} \mathrm{P}<0.05$ vs. control.

(BSA) in an adequate concentration. When indicated, cells $\left(1.0 \times 10^{5}\right.$ in $\left.100 \mu \mathrm{l}\right)$ were incubated with anti-PAR2 antibody $(100 \mu \mathrm{M})$ or paclitaxel $(100 \mathrm{ng} / \mathrm{ml})$ for $1 \mathrm{~h}$ or $\operatorname{U012}(10 \mu \mathrm{M})$ for $15 \mathrm{~min}$ at $37^{\circ} \mathrm{C}$, then placed in the upper compartments. Cells were placed in the upper compartment of the migration chamber with $100 \mu \mathrm{M}$ of PAR2-AP, or/and $100 \mathrm{ng} / \mathrm{ml}$ of LPS in both upper and lower compartments. Cells were allowed to migrate for $18 \mathrm{~h}$ at $37^{\circ} \mathrm{C}$ in $5 \% \mathrm{CO}_{2}$. Cells without any agonists or inhibitors in the assay were used as control. At the end of the assay, the upper surface of the membrane was wiped with a cotton tip applicator to remove non-migratory cells. Cells that had migrated through pores to the lower side of membrane were fixed, stained and counted by light microscopy under high power field $(\mathrm{x} 400)$. For each triplicate, the number of cells in ten high power fields was determined and the counts were averaged.

Western blot analysis. The conditioned cells were collected and the cell lysates were made as follows. The cells were briefly trypsinized, suspended in media with $10 \% \mathrm{FBS}$, pelleted, and resuspended in Tris-buffered saline (TBS) at a density of $10^{6}$ cells per $\mathrm{ml}$, pelleted again, and lysated with $1 \mathrm{ml}$ of lysate buffer (TBS/1\% triton 100/1 mM PMSF). The cell lysates $(5 \mu \mathrm{g})$ were separated by $10 \%$ SDS-polyacrylamide gel electrophoresis (SDS-PAGE) and transferred to PVDF membranes (Bio-Rad, CA, USA). Then, the membranes were blocked with 5\% milk-TBS buffer containing $0.1 \%$ Tween-20 (TBS/Tween) for $1 \mathrm{~h}$ at RT and then probed with the anti-phospho-ERK1/2 (p-ERK1/2), anti-total-ERK1/2 (t-ERK1/2) or anti-phospho-p38MAPK (p-p38MAPK), antitotal-p38MAPK (t-p38MAPK) antibodies. After incubation with different antibodies overnight at $4{ }^{\circ} \mathrm{C}$, the membrane was washed with TBS three times and incubated with (HRP)conjugated second antibodies for $1 \mathrm{~h}$ at RT. Finally, the immunoblots were developed, imaged, and quantitated using a Bio-Rad Fluor-S MultiImager (Typhoon 9400, Amersham, Sweden).

Quantitative real-time PCR analysis. The SW620 cells were treated with different conditions as described above and the total cellular RNA was isolated and first-strand cDNA was synthesized using SuperStrip II reverse transcriptase (Life Technologies). Finally, the Q-PCR was performed in RotorGene 2000 (Corbett Research, Australia). The specific primers used for PCR were as follows: IL-8 forward, 5'-AACATGA CTTCCAAGCTGGCCG-3' and the reverse, 5'-CAGTTT TCCTTGGGGTCCAGAC-3'; TF forward, 5'-TCAGGTGA TCCACCCACCTT-3' and the reverse, 5'-GCACCCAATTT CCTTCCATTT-3'; caspase-7 forward, 5'-TGACCTATCCT GCCCTCA-3' and the reverse, 5'-TCTCCTGCCTCACT GTCC-3'. The control housekeeping gene $\beta$-actin forward, 5'-CACGAAACTACCTTCAACTCC-3', and the reverse, 5'-CATACTCCTGCTTGCTGATC-3'. PAR2 and TLR4 primers were given in 'the assays for PAR2 and TLR4 expression on SW620 cells'. Each pair of primers was shown to give only one product. The Q-PCR parameters consisted of an initial hold at $95^{\circ} \mathrm{C}$ for $5 \mathrm{~min}$, then 35 cycles of $95^{\circ} \mathrm{C}$ for $30 \mathrm{sec}$ and $60^{\circ} \mathrm{C}$ (IL-8, TF) $/ 59^{\circ} \mathrm{C}$ (PAR2) $/ 58^{\circ} \mathrm{C}$ (TLR4) $/ 54.5^{\circ} \mathrm{C}$ (caspase-7) $/ 56^{\circ} \mathrm{C}$ ( $($-actin) for $30 \mathrm{sec}$ and $72^{\circ} \mathrm{C}$ for $30 \mathrm{sec}$. After each Q-PCR run, a melting curve was performed to ensure that only a single amplication was generated. PAR2, TLR4, IL-8, TF and caspase-7 mRNA levels were normalized to control values of $ß$-actin (\%).

Statistical analysis. Data are shown as the mean \pm standard error of the mean (SEM) of triplicate determinations calculated using SPSS software (version 10. 0). $\mathrm{P}<0.05$ was considered statistically significant.

\section{Results}

Cross-inducible expression of PAR2 and TLR4 on SW620 cells. The Q-PCR and flow cytometry analysis revealed that both PAR2 and TLR4 could be originally expressed on SW620 cells at mRNA and protein levels (data not shown). Interestingly, LPS, the ligand of TLR4, could increase PAR2 expression on SW620 cells. As seen in Fig. 1, the PAR2 mRNA was significantly elevated with $100 \mathrm{ng} / \mathrm{ml}$ of LPS treatment in cells at $2 \mathrm{~h}(\mathrm{P}<0.01$ vs. control). However, this stimulating effect of LPS on PAR2 protein changes was not so obvious. On the other hand, PAR2 agonist (PAR2-AP, at $100 \mu \mathrm{M}$ ) could also raise TLR4 mRNA level with the peak at $2 \mathrm{~h}$ of reaction $(\mathrm{P}<0.01$ vs. control). Similarly, the inducing 

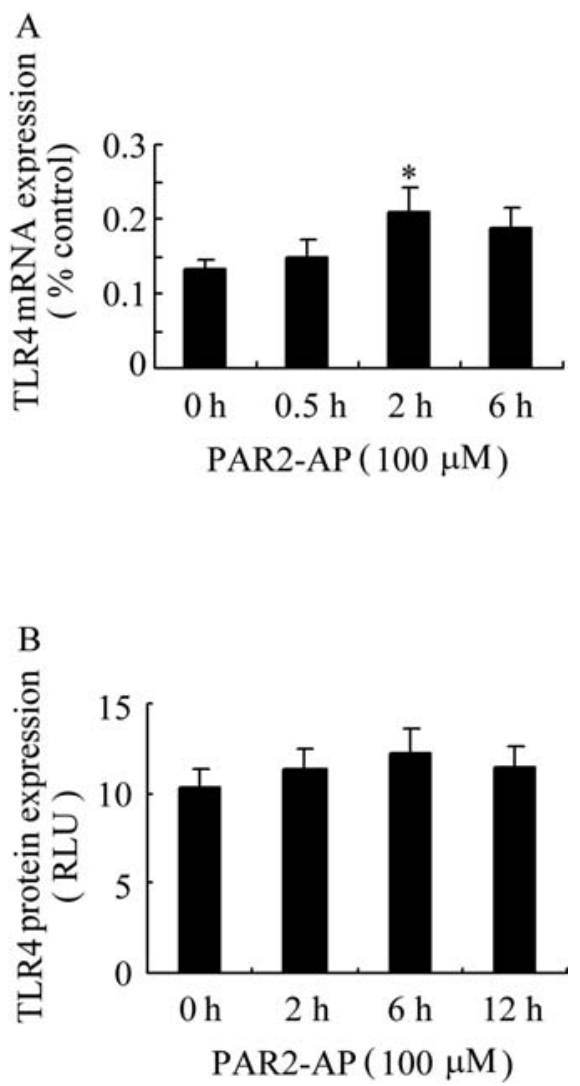

Figure 2. The high release rate of TLR4 induced by PAR2-AP. SW620 cells $\left(1 \times 10^{6} / \mathrm{ml}\right)$ were stimulated by $100 \mu \mathrm{M}$ of PAR2-AP for different times. The cellular RNA was prepared and the Q-PCR was carried out for the TLR4 mRNA determination as described in Materials and methods. The TLR4 protein level was examined by flow cytometry using anti-TLR4 antibody and FITC-labeled second antibody. (A) The TLR4 mRNA level was normalized to control values of $B$-actin (\%). (B) The TLR4 protein level was shown as relative luciferase units (RLU). Data are shown as the mean \pm SEM of triplicate determinations. ${ }^{*} \mathrm{P}<0.05$ vs. control.

effect of PAR2-AP on TLR4 protein expression was not significant (shown in Fig. 2).

The effects of PAR2 and TLR4 activation on SW620 cell proliferation. The SW620 cell growth and proliferation ability was evaluated with different stimulants of PAR2 or/and TLR4, mainly using flow cytometry to observe the cell cycle distribution. As shown in Table I, when the cells were treated with PAR2-AP $(100 \mu \mathrm{M})$, or/and LPS $(100 \mathrm{ng} / \mathrm{ml})$ for $8 \mathrm{~h}$, the $\mathrm{S}$ phase of cells was increased from $25.78 \%$ (untreated cells) to $35.91,34.49,40.06 \%$, respectively. Being coincident with the change of $S$ phase, the rate of $\mathrm{G}_{1}$ phase of cells was decreased with the stimulation of PAR2-AP or/and LPS. Especially, combination of PAR2-AP and LPS had superimposed effects on $\mathrm{S}$ phase of cells $(\mathrm{P}<0.01$ vs. control). Such effects of PAR2-AP and LPS could be blocked by antiPAR2 $(100 \mu \mathrm{M})$ antibody and paclitaxel $(100 \mathrm{ng} / \mathrm{ml})$. The MTT method was also used to confirm these results (data not shown). These results demonstrated that activation of PAR2 or/and TLR4 could promote SW620 cells proliferation.

The effects of PAR2 and TLR4 activation on SW620 cell migration. To test whether PAR2 and TLR4 expressed on colon cancer cells are associated with cell metastasis, we used
Table I. The cell cycle distribution of SW620 cells stimulated with PAR2-AP or/and LPS.

\begin{tabular}{lccc}
\hline Group & $\mathrm{G}_{1}$ phase & $\mathrm{S}$ phase & $\mathrm{G}_{2} / \mathrm{M}$ phase \\
\hline Control & $74.22 \pm 7.16$ & $25.78 \pm 2.66$ & 0.00 \\
PAR2-AP & $64.09 \pm 6.55$ & $35.91 \pm 3.63^{\mathrm{a}}$ & 0.00 \\
Anti-PAR2/PAR2-AP & $72.23 \pm 7.60$ & $27.77 \pm 2.81$ & 0.00 \\
LPS & $65.51 \pm 6.60$ & $34.49 \pm 3.50^{\mathrm{a}}$ & 0.00 \\
Paclitaxel/LPS & $73.03 \pm 7.60$ & $26.97 \pm 2.74$ & 0.00 \\
PAR2-AP/LPS & $59.94 \pm 6.00$ & $40.06 \pm 4.10^{\mathrm{b}}$ & 0.00 \\
\hline
\end{tabular}

SW620 cells $\left(1 \times 10^{6} / \mathrm{ml}\right)$ were stimulated by PAR2-AP $(100 \mu \mathrm{M})$ or/and LPS (100 ng/ml) for $8 \mathrm{~h}$, if necessary, the cells were pretreated with anti-PAR2 $(100 \mu \mathrm{M})$, paclitaxel $(100 \mathrm{ng} / \mathrm{ml})$ for $1 \mathrm{~h}$. The cell cycle distribution of SW620 cells was examined by flow cytometry using propidium iodide (PI) and the proportion of cells within the $\mathrm{G}_{1}, \mathrm{~S}, \mathrm{G}_{2} / \mathrm{M}$ phases was determined ( $\%$, mean $\pm \mathrm{SD}$ ). Data shown as the mean \pm SEM of triplicate determinations. ${ }^{\mathrm{a}} \mathrm{p}<0.05 \mathrm{vs}$. control, ${ }^{b} \mathrm{p}<0.05$ vs. PAR2-AP- or LPS-treated alone.

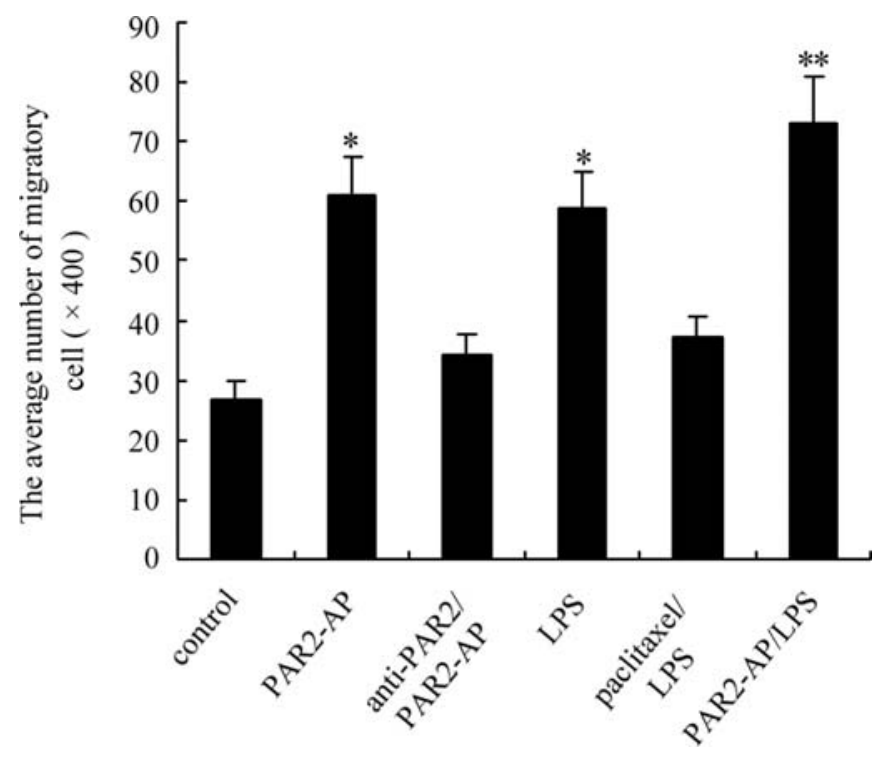

Figure 3. SW620 cell migratory potential measured by modified Boyden Chambers. The cells $\left(1 \times 10^{6} / \mathrm{ml}\right)$ were treated with different agents for $18 \mathrm{~h}$ and the migration assay was carried out as described in Materials and methods. The cells without any agent as a control; PAR2-AP (100 $\mu \mathrm{M})$; LPS (100 $\mathrm{ng} / \mathrm{ml})$; and anti-PAR2 antibody $(100 \mu \mathrm{M})$; paclitaxel $(100 \mathrm{ng} / \mathrm{ml})$. Data shown are the mean \pm SEM of ten fields of triplicate determinations. ${ }^{*} \mathrm{P}<0.05$ vs. control, ${ }^{* *} \mathrm{P}<0.05$ vs. PAR2-AP- or LPS-stimulated alone.

different stimulants or blocking antibody or inhibitor of PAR2 and TLR4 on cell migratory assays. The data showed that number of migratory cells was obviously enhanced after SW620 cells were incubated with PAR2-AP $(100 \mu \mathrm{M})$ or LPS $(100 \mathrm{ng} / \mathrm{ml})$ for $18 \mathrm{~h}(\mathrm{P}<0.05 \mathrm{vs}$. control). Combination of PAR2-AP and LPS had more effects on migration of cells $(\mathrm{P}<0.05$ vs. PAR2-AP or LPS alone). The anti-PAR2 $(100 \mu \mathrm{M})$ antibody and paclitaxel $(100 \mathrm{ng} / \mathrm{ml})$ could block the effects of PAR2-AP or/and LPS (shown in Fig. 3). These results 



Figure 4. The phosphorylation of p38 MAPK in SW620 cells treated with PAR2-AP and LPS. SW620 cells $\left(1 \times 10^{6} / \mathrm{ml}\right)$ were treated with $100 \mu \mathrm{M}$ of PAR2-AP (A) or $100 \mathrm{ng} / \mathrm{ml}$ of LPS (B) for indicated time and p-p38MAPK was determined by Western blotting as described in Materials and methods and normalized to total p38MAPK. Data shown are the mean \pm SEM of triplicate determinations.

indicated that both PAR2 and TLR4 activation could enhance SW620 cell migration.

The effects of PAR2 and TLR4 activation on p38MAPK and ERK1/2 phosphorylation. It is hypothesized by our group that PAR2 and TLR4 activation can affect cellular functions through several different signal transduction pathways. In this study, whether the phosphorylation of p38MAPK or ERK1/2 was regulated through PAR2 or TLR4 activation was investigated. The results showed that the levels of p-p38MAPK in SW620 cells stimulated with PAR2-AP $(100 \mu \mathrm{M})$ or LPS $(100 \mathrm{ng} / \mathrm{ml})$ were not significantly changed, compared with that of untreated cells. Even though the cells were stimulated with PAR2-AP or LPS for $2 \mathrm{~h}$ (Fig. 4). On the contrary, both PAR2-AP and LPS could cause the phophorylation of ERK1/2 at 5 min reaction with SW620 cells, and were timedependent. The maximum p-ERK1/2 was occurred at $15 \mathrm{~min}$ with PAR2-AP treatment and at 30 min with LPS stimulation respectively. Then the phosphorylation of ERK1/2 was
A
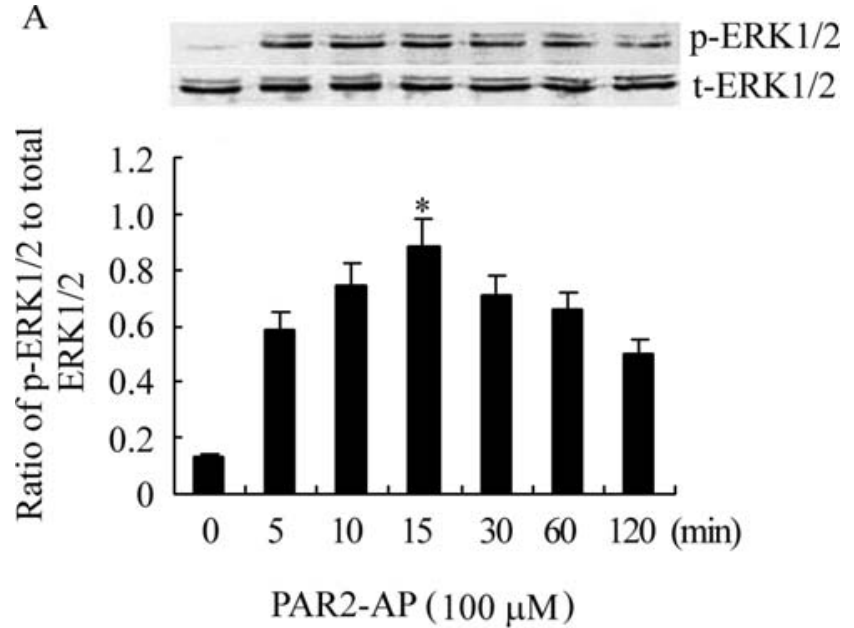

B

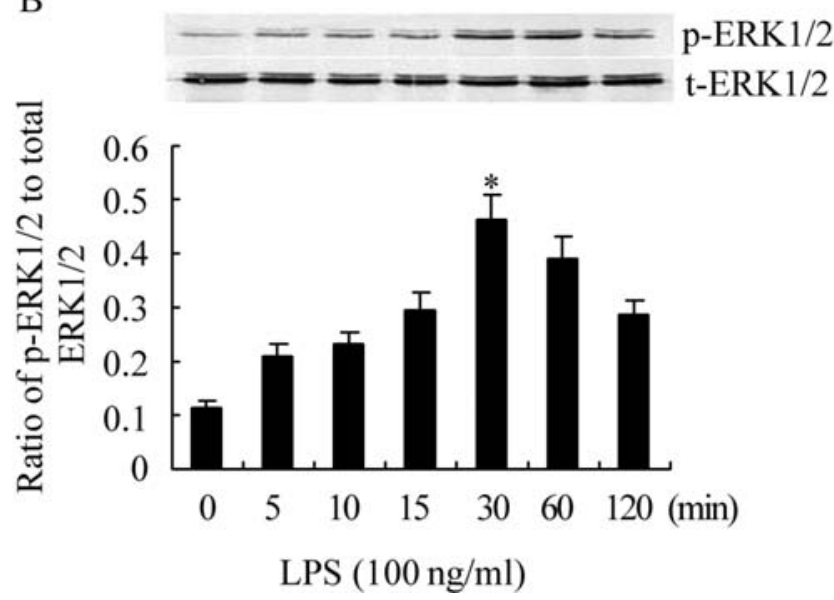

Figure 5. The phosphorylation of ERK1/2 in SW620 cells treated with PAR2-AP and LPS. SW620 cells $\left(1 \times 10^{6} / \mathrm{ml}\right)$ were treated with $100 \mu \mathrm{M}$ of PAR2-AP (A) or $100 \mathrm{ng} / \mathrm{ml}$ of LPS (B) for indicated time and p-ERK1/2 was determined by Western blotting as described in Materials and methods and normalized to total ERK1/2. Data shown are the mean \pm SEM of triplicate determinations. ${ }^{*} \mathrm{P}<0.05$ vs. control.

gradually fell off (shown in Fig. 5). These results demonstrated that both PAR2 and TLR4 activation could induce the phosphorylation of ERK1/2 in SW620 cells.

The effects of PAR2 and TLR4 activation on IL-8, TF and caspase-7 expression. It was also investigated whether some molecules related to cell proliferation, migration and apoptosis could be regulated via PAR2 and TLR4 activation. Our data showed that both PAR2-AP $(100 \mu \mathrm{M})$ and LPS (100 ng/ml) could increase the IL-8 and TF expression at mRNA level in SW620 cells, whereas it decreased the expression of caspase-7 mRNA (Fig. 6). It seemed that the combination of PAR2-AP and LPS had more effect on regulation of IL-8, TF and caspase-7 release, compared to the effects of PAR2-AP or LPS alone, but the difference was not significant.

U0126 intervenes in the effects of PAR2 and TLR4 in SW620 cells. In order to further demonstrate the roles of ERK1/2 phosphorylation via PAR2 and TLR4 activation in SW620 cell, U0126 (the inhibitor of ERK1/2) was used. Once the 


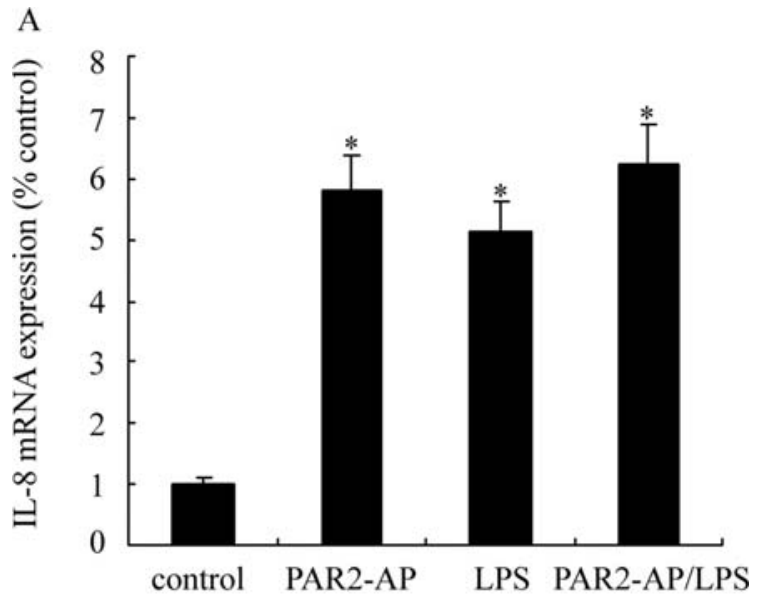

B
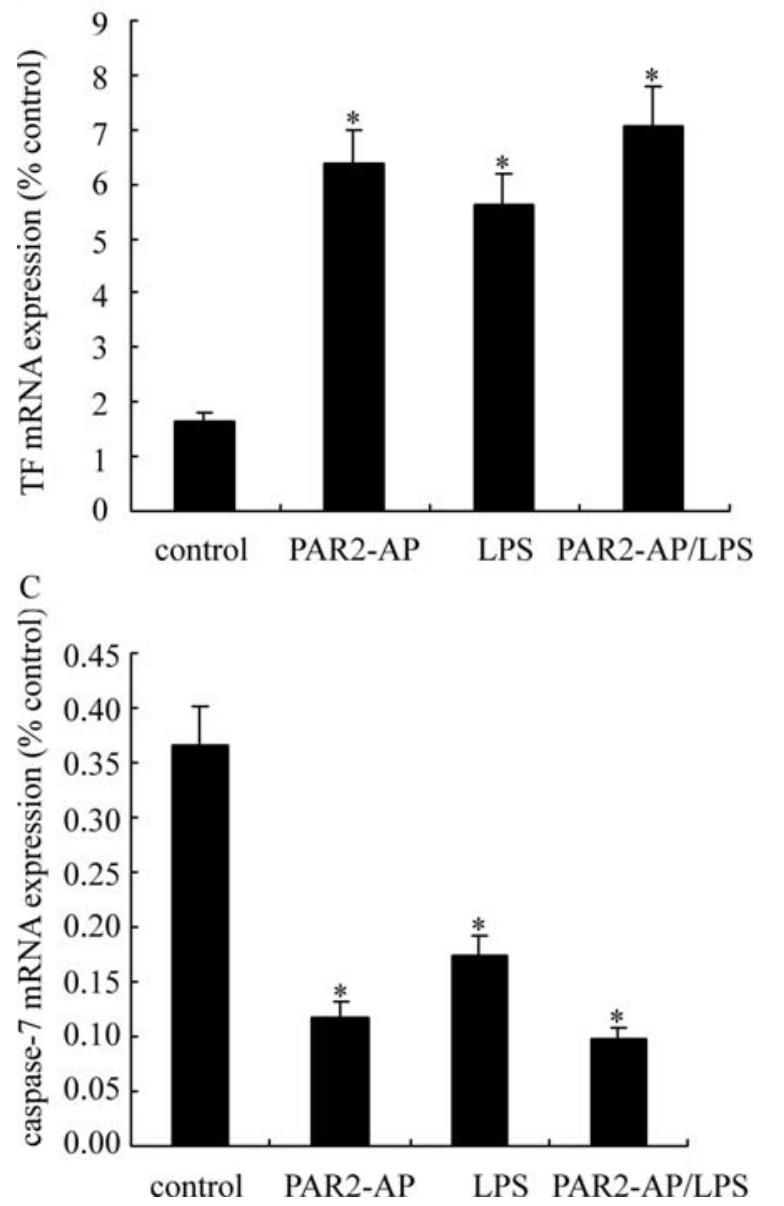

Figure 6. The effects of PAR2-AP and LPS on the expression of IL-8, TF and caspase-7 in SW620 cells. SW620 cells $\left(1 \times 10^{6} / \mathrm{ml}\right)$ were treated in the absence or present of PAR2-AP $(100 \mu \mathrm{M})$ or/and LPS $(100 \mathrm{ng} / \mathrm{ml})$ for $24 \mathrm{~h}$ and the mRNA expression of IL-8 (A), TF (B) and caspase-7 (C) was measured by Q-PCR as described in Materials and methods. Data shown are the mean \pm SEM of triplicate determinations. ${ }^{*} \mathrm{P}<0.05$ vs. control.

cells were pre-incubated with U0126 $(10 \mu \mathrm{M})$ for $15 \mathrm{~min}$, neither PAR2-AP nor LPS had effects on cell proliferation, migration, or the expression of IL-8, TF and caspase-7. As shown in Fig. 7, U0126 at concentration of $10 \mu \mathrm{M}$ could inhibit the promotive effects of PAR2-AP or/and LPS on SW620 cell proliferation and migration. Both the rate of $S$ phase cells (Fig. 7A) and the number of migratory cells (Fig. 7B) were dramatically decreased upon the pretreatment
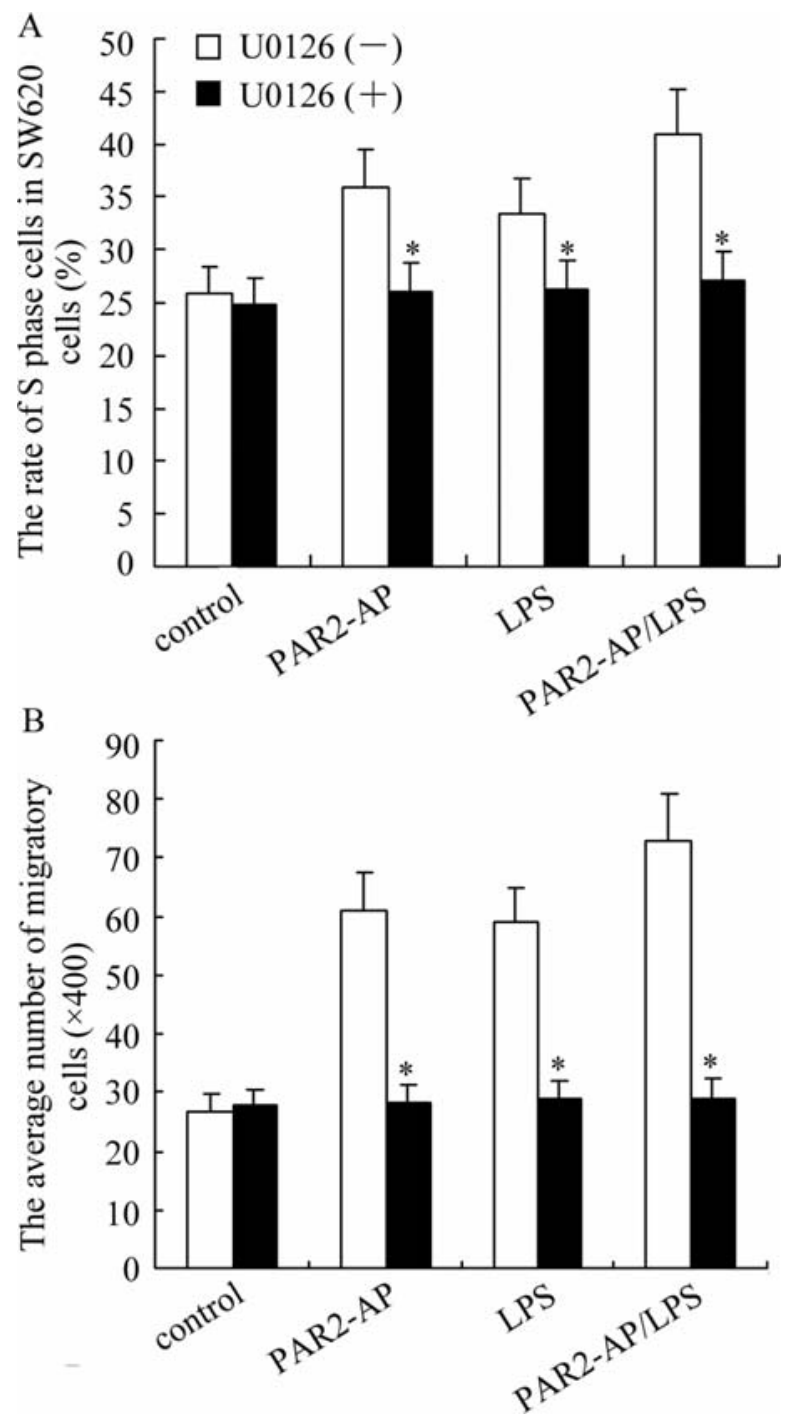

Figure 7. The inhibitory effects of U0126 on the proliferation and migration of SW620 cells. SW620 cells $\left(1 \times 10^{6} / \mathrm{ml}\right)$ were pretreated with $\mathrm{U} 0126(10 \mu \mathrm{M})$ for $15 \mathrm{~min}$, then stimulated with PAR2-AP $(100 \mu \mathrm{M})$ or/and LPS $(100 \mathrm{ng} / \mathrm{ml})$ for $8 \mathrm{~h}(\mathrm{~A})$ or $18 \mathrm{~h}(\mathrm{~B})$. The cell cycle distribution of SW620 cells was examined as described above and the $\mathrm{S}$ phase of cells was mainly shown (A). The cell migratory potential was tested by modified Boyden chambers and the average number of migratory cells was counted in ten fields of triplicate determinations (B). Data shown are the mean \pm SEM of triplicate determinations. ${ }^{*} \mathrm{P}<0.05$ vs. no U0126-treated cells.

with U0126. The data also showed that U0126 could intervene in the regulating effects of PAR2-AP or/and LPS on the mRNA expression of IL-8, TF and caspase-7 in SW620 cells (Fig. 8). All these results further demonstrated that both PAR2 and TLR4 activation on SW620 cells could trigger the phosphorylation of ERK1/2, then regulate the expression of some key molecules, thereby contributing to SW620 cell proliferation and migration.

\section{Discussion}

PARs are expressed in many tumor cells and can be activated by abundant protease in tumor microenvironment generated by tumor cells and host cells. It is believed that PARs are closely associated with cancer cell proliferation, invasion and 

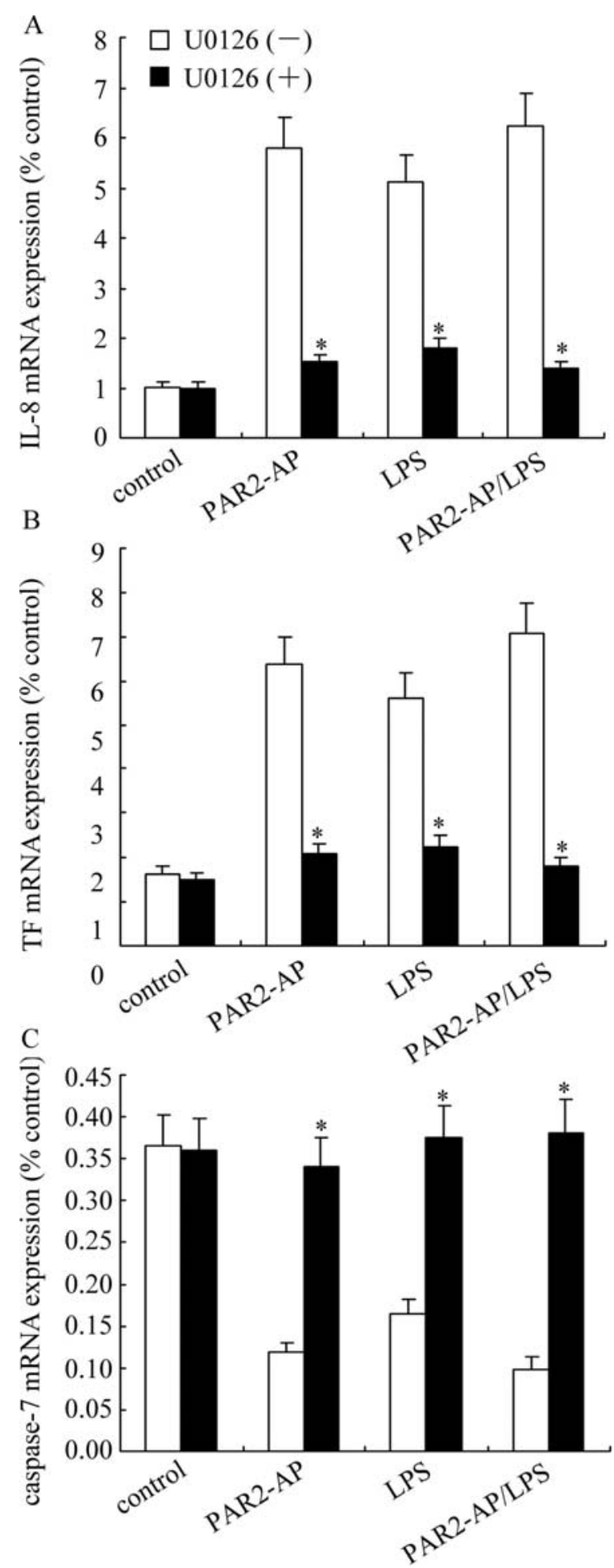

Figure 8 . The counteractive effects of U0126 on the expression of IL-8, TF and caspase-7 in SW620 cells. SW620 cells $\left(1 \times 10^{6} / \mathrm{ml}\right)$ were pretreated with $\mathrm{U} 0126(10 \mu \mathrm{M})$ for $15 \mathrm{~min}$, then stimulated with PAR2-AP $(100 \mu \mathrm{M})$ or/and LPS (100 ng/ml) for $24 \mathrm{~h}$ and the mRNA expression of IL-8 (A), TF (B) and caspase-7 (C) was measured by Q-PCR as described in Materials and methods. Data shown are the mean \pm SEM of triplicate determinations ${ }^{*} \mathrm{P}<0.05$ vs. no U0126 treated cells.

metastasis. Among the members of PARs, PAR2 is generally recognized to be activated by protease not by thrombin and is an important mediator of tumor progression (24). It has been reported that PAR2 expressed in gastric cancer cells is more likely to play an important role in cell growth and EGFR transactivation (25). The coagulant protease VIIa and Xa can promote the migration of breast cancer cells through activating PAR2 (6). Our previous study revealed that PAR2 are strongly expressed on highly metastatic colonic tumor cells SW620 and are linked to cell proliferation and migration (23). Furthermore, we found that the activation of PAR2 with PAR2-AP or factor VIIa could regulate the release of some molecules, e.g. IL-8, TF and caspase-7 (26).

TLRs have emerged as key players in the cross-talk between host and invading microorganisms, on the base of recognition of conserved molecular structures in large groups of pathogens. Recent data clearly indicate that TLRs not only induce an inflammatory response to infection but also associate with certain cancers (27). Well-described TLR4 is one member of TLR family which share structural and functional features. TLR4 are expressed in immune cells and a great variety of tumor cells $(8,11)$. We found that SW620 cells had rich expression of TLR4 at mRNA and protein levels (data not shown). Based on our previous studies indicating PAR2 secretion and function in SW620 cells, it was strongly hypothesized by us that PAR2 might relate with TLR4 in this cell line. Interestingly, it was found that PAR2 activation with its agonist could increase TLR4 mRNA level in cells, and TLR4 activation with LPS also elevated PAR2 mRNA expression, indicating cross-inducible expression between the two receptors. However, the protein levels were only slightly changed in PAR2 and TLR4 (Figs. 1 and 2). These conflictive results with the expression of two receptors are not clearly understood.

Regarding the biological functions of TLR4 on human malignant cells, a few studies on the relations between TLR4 signaling and tumor biological property has been made. On the one hand, tumor-associated macrophages (TAMs) stimulate the production of heat shock proteins and upregulate the expression of some growth factors through TLR4 activating, which in turn promote tumor growth via NF- $\kappa \mathrm{B}$ signal pathway (11). Similarly, TLR4 expressed on lung cancer cells may induce immunosuppressive cytokines and apoptosis resistance, which promote the immune escape of cancer cells (28). On the other hand, the anti-tumor roles of TLR4 have also attracted much attention. TLR ligands might enhance antigen presentation or induce the expression of target molecules, and bring into play the functions of immune response against tumor growth (29). However, what will occur in SW620 cell followed by TLR4 activation? Could there be some cooperation between PAR2 and TLR4? Our data demonstrated that not only PAR2, but also TLR4 activation was able to enhance the proliferative and migratory ability of cells, and the cumulative activation effect of the two receptors was significant (Table I and Fig. 3). The inhibitory antibody of PAR2 and paclitaxel reversed the roles of PAR-AP and LPS, respectively, further demonstrating the effects of PAR2 and TLR4 in SW620 cells. Additionally, paclitaxel is a potent anti-cancer agent, which acts through over-stabilization of cellular microtubules. It has been found that paclitaxel inhibits TLR4 signaling by binding to human TLR4 accessory protein (MD2) (30). Therefore, paclitaxel was used as a TLR4 inhibitor in our experiments.

Through the binding of ligand-receptor, the signals from outside the cell will be transducted into an intracellular 
pathway to regulate the expression of targeted genes and its proteins which affect the cell function. MAPKs are a family of serine/threonine kinases that play important roles in cellular proliferation, differentiation and apoptosis (31). In this study, we found that both PAR2 and TLR4 activation with their agonits trigger the phophorylation of ERK1/2 (not p38 MAPK), and further regulate the secretion of IL-8, TF and caspase-7. These results are coincident with that of other studies in certain cases. For example, it had been reported that ERK1/2 could activate the cascade reactions and regulate the growth and differentiation of tumor cells (32). ERK $1 / 2$ also mediated the IL-8 production in melanoma cells and correlated with cell migration (33). The C-reactive protein (CRP), in a dose- and time-dependent manner, significantly increased the expression and activity of TF via NF-кB and ERK 1/2 MAPK pathway (34). Furthermore, the tumor necrosis factor- $\alpha(\mathrm{TNF} \alpha)$ induced autophagy and cleavage of caspase-7, -8, -9 through ERK1/2 in MCF-7 breast cancer cells (35).

To further demonstrate the effects of PAR2 and TLR4 in SW620 cells through the phophorylation of ERK1/2, the inhibitor of ERK1/2, U0126, was used in our experiments. The results showed that U0126 $(10 \mu \mathrm{M})$ not only inhibited the promotive effects of PAR-AP and LPS on SW620 proliferation and migration, but also attenuated the regulating effects of PAR-AP and LPS on the expression of IL-8, TF and caspase-7. Collectively, our data indicated that PAR2 or/and TLR4 activation on SW620 cells triggered the phosphorylation of ERK1/2, and then provoked the expression of IL-8 and TF, decrease caspase-7 expression in cells, thus promoting colon cancer cell proliferation and migration. The results herein also demonstrate the co-operation between PAR2 and TLR4 on SW620 cells, which is similar to another study on inflammatory responses (36). However, further studies are required as many issues still remain elusive regarding the relationship of the two receptors on different cell types, downstream of their signal transduction pathways, especially in human malignant diseases.

\section{Acknowledgements}

This study was partly supported by grants of National Natural Science Foundation of China (No. 30670907 , 30971301) and Sci-Tech Innovation Team of Jiangsu University (No. 2008-018-02) to Hong Zhou; Student's Scientific Research of Jiangsu University (No. 08A015) to Baocheng Zhou.

\section{References}

1. Ossovskay VS and Bunnett NW: Protease-activated receptors: contribution to physiology and disease. Physiol Rev 84: 579-621, 2004.

2. Kirkland JG, Cottrell GS, Bunnett NW and Corvera CU: Agonists of protease-activated receptors 1 and 2 stimulate electrolyte secretion from mouse gallbladder. Am J Physiol Gastrointest Liver Physiol 293: G335-G346, 2007.

3. Bushell T: The emergence of proteinase-activated receptor- 2 as a novel target for the treatment of inflammation-related CNS disorders. J Physiol 581: 7-16, 2007.

4. Ramachandran R and Hollenberg MD: Proteinases and signalling: pathophysiological and therapeutic implications via PARs and more. Br J Pharmacol 153: S263-S282, 2007.
5. Soreide K, Janssen EA, Körner H and Baak JP: Trypsin in colorectal cancer: molecular biological mechanisms of proliferation, invasion, and metastasis. J Pathol 209: 147-156, 2006.

6. Morris DR, Ding Y, Ricks TK, et al: Protease-activated receptor-2 is essential for factor VIIa and Xa-induced signaling, migration, and invasion of breast cancer cells. Cancer Res 66: 307-314, 2006.

7. Cocks TM and Moffatt JD: Protease-activated receptor-2 (PAR2) in the airways. Pulm Pharmacol Ther 14: 183-191, 2001.

8. Akashi-Takamura S and Miyake K: Toll-like receptors (TLRs) and immune disorders. J Infect Chemother 12: 233-240, 2006.

9. Lu YC, Yeh WC and Ohashi PS: LPS/TLR4 signal transduction pathway. Cytokine 42: 145-151, 2008.

10. Nihon-yanagi Y, Park Y, Ooshiro M, Terai K, Matsumoto T, Murano T and Okazumi S: Expression of toll-like receptor 4 in colorectal cancer. Gan To Kagaku Ryoho 35: 2247-2249, 2008.

11. Zhang YB, He FL, Fang M, et al: Increased expression of Tolllike receptors 4 and 9 in human lung cancer. Mol Biol Rep 36: 1475-1481, 2009

12. Huang B, Zhao J, Li H, et al: Toll-like receptors on tumor cells facilitate evasion of immune surveillance. Cancer Res 65: 5009-5014, 2005.

13. Johnson GL and Lapadat R: Mitogen-activated protein kinase pathways mediated by ERK, JNK, and p38 protein kinases. Science 298: 1911-1912, 2002.

14. Roberts PJ and Der CJ: Targeting the Raf-MEK-ERK mitogenactivated protein kinase cascade for the treatment of cancer. Oncogene 26: 3291-3310, 2007.

15. Le Quément C, Guénon I, Gillon JY, et al: MMP-12 induces IL-8/ CXCL8 secretion through EGFR and ERK1/2 activation in epithelial cells. Am J Physiol Lung Cell Mol Physiol 294: L1076-L1084, 2008.

16. Zhang W and Liu HY: MAPK signal pathways in the regulation of cell proliferation in mammalian cells. Cell Res 12: 9-18, 2002.

17. Liu Y and Mueller BM: Protease-activated receptor-2 regulates vascular endothelial growth factor expression in MDA-MB-231 cells via MAPK pathways. Biochem Biophys Res Commun 344: 1263-1270, 2006.

18. Guha M, O'Connell MA, Pawlinski R, et al: Lipopolysaccharide activation of the MEK-ERK1/2 pathway in human monocytic cells mediates tissue factor and tumor necrosis factor alpha expression by inducing Elk-1 phosphorylation and Egr-1 expression. Blood 98: 1429-1439, 2001.

19. Yao C, Lin Y, Chua MS, et al: Interleukin-8 modulates growth and invasiveness of estrogen receptor-negative breast cancer cells. Int J Cancer 121: 1949-1957, 2007.

20. Khorana AA, Ahrendt SA, Ryan CK, et al: Tissue factor expression, angiogenesis, and thrombosis in pancreatic cancer. Clin Cancer Res 13: 2870-2875, 2007.

21. Lakhani SA, Masud A, Kuida K, et al: Caspases 3 and 7: key mediators of mitochondrial events of apoptosis. Science 311: 847-851, 2006.

22. Ledgerwood EC and Morison IM: Targeting the apoptosome for cancer therapy. Clin Cancer Res 15: 420-424, 2009.

23. Zhou H, Hu H, Shi W, Ling S, Wang T and Wang H: The expression and the functional roles of tissue factor and proteaseactivated receptor-2 on SW620 cells. Oncol Rep 20: 1069-1076, 2008.

24. Sánchez-Hernández PE, Ramirez-Dueñas MG, AlbarranSomoza B, et al: Protease-activated receptor-2 (PAR-2) in cervical cancer proliferation. Gynecol Oncol 108: 19-26, 2008.

25. Caruso R, Pallone F, Fina D, et al: Protease-activated receptor-2 activation in gastric cancer cells promotes epidermal growth factor receptor trans-activation and proliferation. Am J Pathol 169: 268-278, 2006.

26. Zhou H, Shi W, Zhou B, Guo D and Wang T: Tissue factorfactor VIIa regulates interleukin-8, tissue factor and caspase-7 expression in SW620 cells through protease-activated receptor-2 activation. Mol Med Rep 3: 269-274, 2010.

27. Kanczkowski W, Morawietz H, Ziegler CG, et al: Pam3CSK4 and LTA-TLRs ligands associated with microdomains induce IL-8 production in human adrenocortical cancer cells. Horm Metab Res 39: 457-460, 2007.

28. He W, Liu Q, Wang L, et al: TLR4 signaling promotes immune escape of human lung cancer cells by inducing immunosuppressive cytokines and apoptosis resistance. Mol Immunol 44: 2850-2859, 2007.

29. Wolska A, Lech-Maranda E and Robak T: Toll-like receptors and their role in carcinogenesis and anti-tumor treatment. Cell Mol Biol Lett 14: 248-272, 2009. 
30. Resman N, Gradisar H, Vasl J, et al: Taxanes inhibit human TLR4 signaling by binding to MD-2. FEBS Lett 582: 3929-3934, 2008.

31. Blüthgen N and Legewie S: Systems analysis of MAPK signal transduction. Essays Biochem 45: 95-107, 2008.

32. Balmanno $\mathrm{K}$ and Cook SJ: Tumour cell survival signalling by the ERK1/2 pathway. Cell Death Differ 16: 368-377, 2009.

33. Araki K, Shimura T, Yajima T, et al: Phosphoglucose isomerase/autocrine motility factor promotes melanoma cell migration through ERK activation dependent on autocrine production of interleukin-8. J Biol Chem 284: 32305-32311, 2009.
34. Chen Y, Wang J, Yao Y, et al: CRP regulates the expression and activity of tissue factor as well as tissue factor pathway inhibitor via NF-kappaB and ERK 1/2 MAPK pathway. FEBS Lett 583: 2811-2818, 2009

35. Sivaprasad U and Basu A: Inhibition of ERK attenuates autophagy and potentiates tumour necrosis factor-alpha-induced cell death in MCF-7 cells. J Cell Mol Med 12: 1265-1271, 2008.

36. Rallabhandi P, Nhu QM, Toshchakov VY, et al: Analysis of proteinase-activated receptor 2 and TLR4 signal transduction. J Biol Chem 283: 24314-24325, 2008. 